\title{
CONSTRUÇÃO DISCURSIVA DE IDENTIDADES SOCIAIS: ENTRE O BOM E O MAU
}

\author{
ALCIONE GONÇALVES CAMPOS ${ }^{1}$ \\ Programa de Pós-Graduação em Estudos da Linguagem \\ Universidade Estadual de Londrina \\ Instituto de Educação Ciência e Tecnologia Fluminense - IFFluminense \\ Rodovia BR 356, Km 3 - 28300-000 - Itaperuna-RJ - Brasil \\ alcionegcampos@gmail.com
}

\begin{abstract}
Resumo. Neste artigo, tenho como objetivo principal analisar, em um texto de opinião publicado no "Jornal de Londrina", a construção discursiva de identidades sociais. Tendo como aporte teórico-analítico a Análise de Discurso Crítica e a Semântica Argumentativa, desenvolvo análise que demonstra que a seleção lexical é o principal mecanismo linguísticoargumentativo usado junto com a avaliação modalizadora para encadear os argumentos e direcionar a construção de sentido para o argumento final. As escolhas lexicais feitas dão um efeito de oposição entre o que é bom e mau, desejável e indesejável, e culmina com a argumentação pela punição do mau. Assim, esse discurso age na construção social da realidade e das identidades dos sujeitos.
\end{abstract}

Palavras-chave: discurso; semântica argumentativa; identidade.

\begin{abstract}
The main objective of this article is to analyze the discursive construction of social identities in an opinion text published by "Jornal de Londrina". The theoretical and analytical framework used is the Critical Discourse Analysis and Argumentative Semantics. The analysis developed showed that the lexical selection is the main linguistic-argumentative mechanism used along with modal evaluation to chain arguments and construct sense for the final argument. The lexical choice creates a dichotomy between good and bad, desirable and undesirable and culminate with the argument for the punishment of what is bad and not desirable. This discourse, therefore, acts upon social construction of reality and subject identities.
\end{abstract}

Keywords: discourse; argumentative semantics; identity.

\section{Introdução}

A linguagem, entendida como discurso, é uma forma de representar o mundo em seus diferentes aspectos: o mundo material, o mundo mental de sentimentos e valores, e o mundo social (FAIRCLHOUGH, 2003). A forma como representamos esses aspectos

\footnotetext{
${ }^{1}$ Doutoranda em Estudos da Linguagem no Programa de Pós-Graduação em Estudos da Linguagem da Universidade Estadual de Londrina (UEL). Professora no Instituto de Educação Ciência e Tecnologia Fluminense - IFFluminense (Campus Itaperuna).
} 
está condicionada à nossa posição no mundo, nossas experiências e às nossas relações com outras pessoas. Essas representações são materializadas em textos de diferentes gêneros por meio de diferentes recursos linguísticos. Além de representar o mundo, ao usarmos a linguagem, construímos e reconstruímos simbolicamente identidades sociais. A forma como usamos a linguagem, a seleção lexical que fazemos, é parte da tessitura do texto e da tessitura de identidades, de si e de outros (FAIRCLOUGH, 2003).

Para Pires de Oliveira (2004), a linguagem é uma "argumentalogia", pois, quando falamos, não estamos trocando informações sobre o mundo, "falamos para construir um mundo e a partir dele tentar convencer nosso interlocutor da nossa verdade, verdade criada pelas e nas nossas interlocuções" (PIRES DE OLIVEIRA, 2004, p. 28). Koch (1984) acrescenta que a linguagem veicula ideologia e por meio dela expressamos nosso posicionamento e objetivamos persuadir, convencer nossos interlocutores. "A finalidade última de todo ato de comunicação não é informar, mas é persuadir o outro a aceitar o que está sendo comunicado. A linguagem é sempre comunicação e, portanto, persuasão" (FIORIN, 2005, p. 52).

Entendendo que a linguagem é uma forma de representar o mundo e seus aspectos, construir identidades sociais e persuadir interlocutores, analiso neste artigo um texto de opinião de autoria de um professor universitário, publicado em novembro de 2011 no "Jornal de Londrina". Esse texto incide sobre as identidades sociais de estudantes, exprime uma visão de mundo particular e transmite uma ideologia que busco abordar com base na Semântica Argumentativa, por meio da análise das marcas linguísticas usadas no encadeamento argumentativo do texto.

$\mathrm{Na}$ sequência a esta introdução, discorro sobre a fundamentação teórica, a conceituação de identidade na qual me embaso, e sobre o quadro teórico da semântica argumentativa. Em seguida, desenvolvo a análise e teço comentários sobre as interpretações analíticas. Por fim, faço algumas ponderações, aliando os embasamentos teóricos à análise.

\section{Fundamentação teórica}

\subsection{Identidade}

Tem-se observado atualmente um crescente interesse em discussões teóricas em torno do conceito de identidade. Essas discussões são relativamente novas na história da humanidade, pois, no passado, acreditava-se na existência do "eu" imutável. Com o surgimento da ideia de um sujeito que se estrutura a partir de relações com outras pessoas em contextos sociais e históricos específicos, emerge a concepção de indivíduo pósmoderno, segundo a qual a identidade é múltipla e dinâmica. "As velhas identidades, que por tanto tempo estabilizaram o mundo social, estão em declínio, fazendo surgir novas identidades e fragmentando o indivíduo moderno, até aqui visto como um sujeito unificado" (HALL, 2011a, p. 7). O sujeito pós-moderno, que não tem sua identidade estruturada em torno de um "eu" coerente, passa a ser entendido como um ser em constante transformação, uma produção histórica, social, cultural e discursiva, definido 
por relações interpessoais. Com isso, aumenta o interesse em entender as relações e os contextos que influenciam a constituição de identidades.

Os vários teóricos e estudiosos que têm se interessado pela temática da identidade, a fim de buscar entendê-la e defini-la em diversas áreas do conhecimento, "de uma forma ou de outra, criticam a ideia de uma identidade integral, originária e unificada" (HALL, 2011b, p. 103).

Em geral, o conceito de identidade tem diferentes significados na literatura. $\mathrm{O}$ que estes vários significados têm em comum é a ideia de que a identidade não é um atributo fixo de uma pessoa, mas um fenômeno relacional. O desenvolvimento da identidade ocorre em um campo intersubjetivo e pode ser melhor caracterizado como um processo em andamento. (BEIJAARD; MEIJER; VERLOOP, 2011, p. 3)

O teórico cultural Stuart Hall (2011a), ao explorar questões sobre a identidade cultural na modernidade tardia ${ }^{2}$, afirma que o mundo social está passando por um processo de mudanças que está deslocando as sociedades modernas e desestabilizando suas referências. Essa perda de referências estáveis e unificadas afeta também os sujeitos, tanto na sua relação com o mundo social como consigo mesmos. Esse descentramento do sujeito, "esse duplo deslocamento - descentração dos indivíduos tanto de seu lugar no mundo social e cultural quanto de si mesmos - constitui uma "crise de identidades" para o indivíduo" (HALL, 2011a, p. 9). Esse entendimento parece ser compartilhado pelo sociólogo Giddens (2002), que aborda a questão da identidade enfocando as mudanças na vida social. Este autor defende que mudanças institucionais acarretadas pela modernidade tardia perpassam e afetam os aspectos mais pessoais, as características mais íntimas de nossa existência. $\mathrm{O}$ que leva o indivíduo a perceber-se como fragmentado na mesma medida em que percebe suas referências sociais como deslocadas e fragmentadas.

Woodward (2011) também discute a desestabilização de estruturas supostamente fixas e a crise identitária que se liga a esse processo. Para a autora, as transformações sociais, políticas e econômicas sofridas na modernidade tardia são a causa dessa nova percepção de instabilidade. Com isso, a identidade ou os processos de identificação são afetados e passam a refletir as características do contexto no qual se desenvolvem. Portanto, em oposição a perspectivas essencialistas que sugerem haver algo de fixo, autêntico e cristalino na identidade, esta passa a ser considerada como fluida, contingente e efêmera.

Nessa discussão, a autora considera problemático analisar identidades a partir de oposições binárias fixas. Por isso, propõe o uso do conceito de différance desenvolvido pelo filósofo da linguagem Derrida (1978), que sugere "uma alternativa ao fechamento e à rigidez das oposições binárias. Em vez de fixidez, o que existe é contingência. $\mathrm{O}$ significado está sujeito ao deslizamento" (apud WOODWARD, 2011, p. 54). Assim, Woodward (2011) define identidade como sendo um processo relacional e marcada pela

\footnotetext{
${ }^{2}$ Hall (2011a) utiliza o termo "modernidade tardia" com referência ao período posterior aos anos 60 . Ele afirma que esse é um período marcado por mudanças estruturais da sociedade e, consequentemente, mudanças nas identidades dos sujeitos. Esse autor também utiliza o termo pós-mordernidade com o mesmo sentido. Autores como Giddens (2002) e Chouliaraki e Fairclough (1999) optam pelo termo "modernidade tardia" (em inglês, late modernity).
} 
diferença. Sua existência é dependente de uma outra identidade que ela não é, ou seja, ela se caracteriza por um não ser, por uma identidade que difere dela, mas que, no entanto, existe por causa dela. Para Woodward (2011, p. 56), as identidades são constituídas nessa relação de diferença com outras identidades, por nossas subjetividades aliadas ao "contexto social no qual a linguagem e a cultura dão significado à experiência que temos de nós mesmos". Portanto, as múltiplas identidades que assumimos no decorrer de nossas vidas são constituídas em processos relacionais, marcadas por interações simbólicas subjetivas e ligadas ao contexto social e histórico a que pertencemos.

A visão de identidades fluidas e mutáveis, constituídas socialmente e marcadas por questões subjetivas, está relacionada às identidades definidas como construções sociais e discursivas, uma vez que os encontros interacionais que temos vão moldando nossa visão de mundo e de nós mesmos (MOITA LOPES, 2002). Nessa perspectiva, as identidades não são consideradas inatas, mas fluidas e construídas no discurso. Para (ORLANDI, 2012), as relações de sujeitos e sentidos nas quais as identidades sociais são constituídas, são múltiplas, variadas, heterogêneas, fragmentadas, contraditórias e em constante fluxo, fazendo parte das práticas discursivas nas quais atuamos. Discursos e identidades estão imbricados, pois, ao mesmo tempo em que interagimos no mundo através da linguagem, construímos o mundo, a nós mesmos e outros em um processo contínuo e dinâmico.

\subsection{Análise de Discurso Crítica (ADC)}

A abordagem teórico-metodológica que dá suporte a este estudo é a da Análise de Discurso Crítica (ADC). De cunho heterogêneo, essa abordagem se caracteriza por sua interdisciplinaridade, estando composta por uma série de perspectivas que se inserem em estudos críticos do discurso ${ }^{3}$. A vertente que adoto é a Teoria Social do Discurso proposta por Norman Fairclough (1995, 2003, 2006, 2012) e Chouliaraki e Fairclough (1999). Essa vertente da ADC é uma abordagem científica transdisciplinar de estudos críticos de discurso textualmente orientada, que entende a linguagem, enquanto discurso, como parte irredutível da vida social, dialeticamente interligada a outros elementos, e ressalta a importância de sua análise em investigações de questões sociais. Sendo, portanto, uma versão dialético-relacional (FAIRCLOUGH, 2012) da ADC.

A vida social, nessa perspectiva, é composta por três níveis: a estrutura social mais abstrata, o evento social mais concreto e o nível intermediário mediador, a prática social. As estruturas sociais são entidades abstratas que determinam um potencial de possibilidades passíveis de se materializarem nos eventos sociais, que correspondem às realizações concretas mediadas pela entidade intermediária, ou seja, as práticas sociais. Estas "podem ser entendidas como formas de controlar a escolha de algumas possibilidades e a exclusão de outras" , afirma Fairclough (2003, p. 23), e também de manter essas escolhas por um período de tempo em certas áreas da vida social. Portanto, o conceito de prática social refere-se a uma entidade intermediária, situada entre as estruturas sociais mais fixas e as ações individuais mais flexíveis nos eventos sociais.

\footnotetext{
${ }^{3}$ Ruth Wodak e Michael Meyer (2012) oferecem uma revisão de abordagens inseridas no campo da ADC.

${ }^{4}$ Todas as traduções dos originais em inglês foram livremente feitas pela autora.
} 
A linguagem é parte integrante e irredutível dos três níveis da vida social, em outras palavras, há uma dimensão semiótica para cada um desses níveis. A linguagem figura na estrutura social como sistema semiótico (rede de opções léxico-gramaticais); no nível intermediário das práticas sociais, a linguagem é discurso (redes de ordem do discurso), e, no nível mais concreto, a linguagem é texto ${ }^{5}$ (materialização do discurso em material empírico). A linguagem em uso (discurso) nas práticas sociais é baseada nas estruturas semióticas e tem, ao mesmo tempo, uma flexibilidade que permite a manifestação da individualidade nos textos.

Figurando como discurso nas práticas sociais, a linguagem é ao mesmo tempo uma forma de ação (gêneros), de representação (discursos) e de identificação (estilos). Gêneros, discursos e estilos se articulam formando a ordem do discurso. Um gênero é uma forma de agir linguisticamente. Discursos são formas de representar aspectos do mundo físico, social ou mental. Estilos são formas de ser, de constituir as identidades dos atores envolvidos no evento social por meio da linguagem. Os gêneros, discursos e estilos se materializam no texto por meio de formas e significados linguísticos que são chamados significado acional, representacional e identificacional, respectivamente. Tais significados são sempre simultâneos nos textos, no entanto, dependendo do escopo do estudo, a análise pode variar o foco entre um ou outro.

Nesse artigo, tenho como objetivo analisar a constituição de identidades sociais de estudantes em um artigo de opinião. Este texto foi escrito por um professor universitário a respeito de movimentos estudantis. $\mathrm{O}$ foco da análise recai sobre uma prática social de expressividade simbólica por meio de um gênero da esfera jornalística. Para esse próposito, desenvolvo a análise do significado identificacional, utilizando categorias linguísticas da Semântica Argumentativa.

\subsection{Semântica Argumentativa}

O referencial analítico usado neste estudo está embasado em categorias advindas da Semântica Argumentativa, também chamada de Semântica da Enunciação, que "enfatiza o intercâmbio entre os interlocutores na situação discursiva e dos variados fatores intervenientes em um ato de comunicação" (OLIVEIRA, 2004, p. 122). Ainda segundo Oliveira (2004), a Semântica Argumentativa, considerada um ramo da pragmática, está interessada nas relações entre locutor e alocutário, e nos procedimentos argumentativos que direcionam a construção de sentido.

Para Ducrot (1991), a argumentação é uma característica essencial da língua, é inerente à atividade linguística, e a construção de sentido depende de mecanismos diversos ligados à estrutura semântica da língua. $\mathrm{O}$ autor chama esses mecanismos de marcas linguísticas que são os elementos responsáveis pelos efeitos de sentido e pelo direcionamento argumentativo do enunciado.

Koch (1984) considera "que o ato de argumentar constitui o ato linguístico fundamental" e que a todo discurso subjaz uma ideologia, não havendo, portanto, discurso neutro. Para a autora, a linguagem é um ato de persuasão e todo discurso é um ato

${ }^{5}$ Fairclough (2003) usa o termo 'texto' de forma abrangente. Textos podem ser escritos, falados, visuais ou multimodais. 
comunicativo por meio do qual o enunciador transmite uma ideologia. Nesse sentido, a Semântica Argumentativa fornece embasamento teórico e aporte analítico para o estudo do discurso e da ideologia a ele subjacente por meio da análise das marcas linguísticas presentes no texto ${ }^{6}$. Para Fiorin (1990, p. 11), "o discurso são as combinações de elementos linguísticos (frases ou conjuntos constituídos de muitas frases), usados pelos falantes com o propósito de exprimir seus pensamentos, de falar do mundo exterior ou de seu mundo interior, de agir sobre o mundo". Concepção que se coaduna com o que é defendido por Fairglough (2003) em suas considerações acerca de discurso. Para estes autores, o texto é entendido como a materialização linguística do discurso. Por isso, analisar as marcas linguísticas presentes no texto, o material empírico, é analisar discurso.

Essas marcas linguísticas, usadas pelo locutor "com o objetivo de comunicar valores, expressar uma ideologia e persuadir o interlocutor, em um complexo processo de manipulação" (OLIVEIRA; AZEVEDO; NASCIMENTO, 2008, p. 122), são várias. Abordarei algumas dessas marcas, as quais fazem o encadeamento argumentativo e direcionam a construção de sentido do enunciado, culminando com a argumentação final. São elas: a seleção lexical e a avaliação modalizadora.

A seguir apresento o texto na íntegra, para melhor visualização dos recursos, e, na sequência, inicio a análise, na qual abordo os dois mecanismos linguísticoargumentativos mencionados acima, a seleção lexical, com ênfase nos adjetivos e substantivos, e a avaliação modalizadora, ambos fundamentais para a construção de sentido no texto analisado.

\section{Análise}

\section{Ponto de vista}

Há de se reconhecer e valorizar o movimento estudantil no desenvolvimento democrático do Brasil. Quando são organizados, os estudantes conseguem mobilizações importantes e o grito de alerta sempre ecoa com bons resultados comunitários. Mas, nos últimos anos, o que temos vivenciado e assistido não reflete o verdadeiro e legítimo movimento estudantil. Estão muito mais para um grupo de terroristas, criados nos becos escuros dos partidos políticos contrários aos contras.

Nas universidades públicas brasileiras esses sequazes de Guevara encontram condições propícias para se multiplicarem. Adentram nos cursos considerados fáceis por pouca procura, sobretudo nas Ciências Humanas, vivem uma graduação, depois uma pós-graduação e mais adiante outra graduação. Em síntese: são predadores do dinheiro público por dez anos consecutivos, vivendo em moradia estudantil e comendo quase de graça nos restaurantes universitários. Encontram à disposição salas para reuniões, alegando que o espaço é público. Fazem festas para comemorar o nada e o inútil, fumam maconha por quase todo o campus e deixam o cabelo e barba crescerem para homogeneizar o fenótipo de guerrilheiros. Desafiam as leis, alegando perseguição da polícia e exigindo liberdade à contravenção. Em nada produzem ao País. Não são capazes de criar algo que melhore a vida do homem. Não possuem capacidade e até mesmo vontade para inovar com qualquer tecnologia ou aprendizado. São hematófagos, mal cheirosos e arrogantes. Em média possuem 30 anos de idade, homens e mulheres, o que certamente nos leva a questionar quem são, de fato, esses encapuzados? Chamar esses pequenos baldados de estudantes é uma afronta aos

\footnotetext{
${ }^{6}$ Texto é entendido como a materialização linguística do discurso (FIORIN, 1990).
} 
decentes discentes de nosso País. O verdadeiro estudante brasileiro tem família, ideias e ideais. Essa frívola tribo que fez da USP uma notícia policial indesejada não pode ser chamada de movimento estudantil. São alienados e fúteis, criados com a garapa amarga do ódio e induzidos por militantes de ultraesquerda de partidos políticos e sindicatos de macarronadas, cujos "líderes" se esqueceram de acordar e não enxergam que o Brasil já é outro, bem diferente dos tempos da ditadura. Um bando de preguiçosos que querem a mídia como emblema de existência. É uma espécie em extinção. É só uma questão de tempo. Destruir o patrimônio público e impedir as pessoas de bem e trabalhadoras de ir e vir já são motivos suficientes para enviar esses nocivos bandidos para o lugar que lhes é peculiar na origem embrionária: a cadeia.

Wilmar Marçal é professor universitário em Londrina

\subsection{Seleção lexical}

Quando o locutor emite um discurso, ele verbaliza sua visão de mundo, exprime seus pensamentos e age no mundo. Nesse momento, ele está diante de escolhas linguísticas, sintáticas e lexicais, e entre dois tipos de formulação discursiva, o discurso objetivo e o subjetivo (KERBRAT-ORECCHIONI, 1999). No discurso objetivo, há um esforço do locutor para não se implicar, ao passo que, no discurso subjetivo, o locutor se implica, explícita ou implicitamente. Essa implicação é determinada pelas escolhas lexicais, as quais definem o envolvimento afetivo do locutor e a avaliação ou apreciação que ele faz do referente.

A seleção lexical é, pois, um dos mecanismos dos quais o locutor lança mão na argumentação. A partir da estratégia da escolha lexical, se estabelecem as oposições, os jogos de palavras, as metáforas etc. A seleção lexical inclui escolhas de substantivos, adjetivos, advérbios derivados ou correspondentes a adjetivos e verbos (MARTINS, 1989). Nesta análise, focalizarei a seleção de adjetivos e substantivos, pois considero serem os de maior destaque na construção argumentativa do texto.

A análise da adjetivação pode revelar uma visão particular e avaliação do mundo, sugere Da Cal (1969). Além disso, é um mecanismo argumentativo subjetivo e, como afirmam Oliveira, Azevedo e Nascimento (2008, p. 130), é um "recurso persuasivo que, normalmente, envolve, de forma emocional", o interlocutor, conduzindo-o à construção de sentido almejada pelo locutor. Pode-se afirmar que o mesmo acontece com a seleção dos substantivos. Sua escolha é primordial na argumentação e construção de sentido.

Kerbrat-Orecchioni (1999) classifica os adjetivos em objetivos e subjetivos. Os subjetivos são subdivididos em afetivos e avaliativos. E, finalmente, os avaliativos são subdivididos em axiológicos e não axiológicos. Essa autora afirma que os adjetivos objetivos são aqueles que transmitem uma característica do objeto independente da subjetividade do locutor. Já os adjetivos afetivos enunciam ao mesmo tempo uma propriedade do objeto que determinam e uma reação emocional do locutor em relação a esse objeto. Os adjetivos avaliativos axiológicos, por sua vez, transmitem um julgamento de valor moral, daquilo que é bom ou mau, útil ou inútil, desejável ou indesejável. E, os adjetivos avaliativos não axiológicos não transmitem julgamento de valor ou engajamento afetivo do locutor. Eles sugerem uma avaliação quantitativa ou qualitativa do objeto que determinam. No entanto essa avaliação depende da subjetividade do locutor, por isso, são categorizados como subjetivos e não objetivos. Na análise do texto, veremos que os 
adjetivos afetivos e avaliativos axiológicos são os de maior destaque e revelam o envolvimento emocional do locutor e a transmissão de valores na trama argumentativa.

Os substantivos, segundo classificação de Kerbrat-Orecchioni (1999), podem ser objetivos e axiológicos. Os objetivos são aqueles que enunciam uma característica, uma propriedade objetiva e verificável do referencial. Os substantivos axiológicos são aqueles que, além de descrever, emitem uma avaliação de apreciação ou depreciação sobre o referencial.

No texto de Wilmar Marçal, é possível perceber o antagonismo que ele estabelece entre o bem e o mau, o desejável e o indesejável, o "verdadeiro estudante brasileiro" e os "guerrilheiros malcheirosos". Para isso, o locutor utiliza uma cuidadosa seleção de substantivos e adjetivos que fazem o encadeamento argumentativo e dão sentido ao seu argumento final.

O texto é iniciado com a valorização positiva de movimentos estudantis no desenvolvimento democrático do país. Porém, há uma restrição. Os movimentos e mobilizações estudantis que devem ser reconhecidos e valorizados, pois conseguem resultados, são aqueles organizados e conduzidos por "verdadeiros" estudantes. Essa valoração positiva é expressa quase que unicamente pelos adjetivos usados, os quais são axiológicos (expressam julgamento de valor moral). Kerbrat-Orecchioni (1999) ressalta que a valoração moral não é uma característica intrínseca do adjetivo, mas está relacionada ao seu uso em uma determinada sociedade e momento histórico. Entendo que, na sociedade e momento histórico em que vivemos, os adjetivos usados transmitem um julgamento de valor. $\mathrm{O}$ adjetivo democrático, por exemplo, não é uma palavra neutra em nossa sociedade. Ele está carregado de uma ideologia, e tem valoração positiva.

Os substantivos, por outro lado, são objetivos, imparciais, neutros, não transmitem um julgamento de valor. O quadro 01 ilustra essa qualificação.

Quadro 01. Valoração positiva de estudantes.

\begin{tabular}{|c|c|}
\hline SUBSTANTIVOS & ADJETIVOS \\
\hline movimento & democrático \\
\hline desenvolvimento & organizados \\
\hline estudantes & importantes \\
\hline mobilizações & bons \\
\hline resultados & comunitários \\
\hline & verdadeiro \\
\hline & legítimo \\
\hline & que tem família \\
\hline & que tem ideias \\
\hline & que tem ideais \\
\hline
\end{tabular}

Em seguida, o locutor utiliza o operador argumentativo mas e passa a tratar do movimento estudantil indesejável, ruim. Aquele que se opõe ao movimento verdadeiro e legítimo. Que o locutor caracteriza como conduzido por "um grupo de terroristas, criados nos becos escuros dos partidos políticos contrários aos contras". Ele utiliza uma série de adjetivos e substantivos pejorativos para qualificar os estudantes. Entre esses, destaco o 
substantivo terrorista, que remete à memória de grandes crimes contra a sociedade. $\mathrm{O}$ uso de predadores e hematófagos remete à questão de sobrevivência às custas de outrem. $\mathrm{O}$ efeito produzido é o de que a sociedade fornece subsídios para essas pessoas que não darão nada em troca, são inúteis. O locutor utiliza o operador argumentativo sobretudo para enfatizar que esses estudantes indesejáveis são da área das Ciências Humanas, reforçando um estereótipo de inferioridade atribuída a uma área do conhecimento.

Os adjetivos usados vão reforçando o efeito de sentido de que esse grupo de estudantes é, na verdade, um grupo de bandidos. Eles remetem a imagens historicamente construídas de grupos e situações relacionadas a conflitos e crimes como o termo sequazes de Guevara e que fumam maconha. Além de desacreditá-los, ao lhes conferir uma imagem de inutilidade para a sociedade com o uso de adjetivos, como preguiçosos e fúteis. O quadro 02 ilustra os adjetivos e substantivos usados.

Quadro 02. Valoração pejorativa de estudantes.

\begin{tabular}{|c|c|}
\hline SUBSTANTIVOS & ADJETIVOS \\
\hline terrorista & sequazes de Guevara \\
\hline predadores & que fumam maconha \\
\hline hematófagos & que comemoram o nada e o inútil \\
\hline bandidos & que deixam cabelo e barba crescerem \\
\hline & Guerrilheiros \\
\hline & que nada produzem ao país \\
\hline & que não são capazes de criar \\
\hline & mal cheirosos \\
\hline & Arrogantes \\
\hline & que não possuem capacidade ou até mesmo vontade inovar \\
\hline & pequenos baldados \\
\hline & Frívola \\
\hline & Alienados \\
\hline & Fúteis \\
\hline & Preguiçosos \\
\hline & Nocivos \\
\hline
\end{tabular}

A partir da escolha dos substantivos e adjetivos usados pelo locutor, fica clara a oposição entre os dois grupos de estudantes. O primeiro grupo, ao qual ele se refere como grupo de estudantes legítimos, é valorizado e desejado na sociedade. O segundo grupo, referido como grupo de terroristas e inúteis, os quais pertencem à área das Ciências Humanas, não é bom para a sociedade.

Assim, o locutor contrapõe o estudante legítimo, aquele que tem direito de se manifestar, a um grupo que se refere como guerrilheiros, terroristas. Estes são caracterizados como improdutivos, inúteis, enquanto aqueles seriam responsáveis pelo futuro do país. O locutor cria, por meio de seu discurso, duas imagens antagônicas de estudantes. A primeira parece ser a dos estudantes de classe média que geralmente têm seus estudos universitários custeados por suas famílias, já a segunda imagem refere-se ao estudante que depende de auxílios públicos, como moradia estudantil, para se graduarem. Esse segundo grupo de estudantes é, então, vinculado à imagem não apenas negativa, mas 
também relacionada ao crime, ao se usar atributos como terrorista. O texto cria, assim, um efeito de sentido de que esses estudantes não merecem ser chamados de estudantes, pois não se adequam ao perfil do verdadeiro estudante. Eles são, ao contrário, criminosos que depredam o patrimônio e fazem mal uso do dinheiro público.

\subsection{Avaliação modalizadora}

Outro mecanismo argumentativo relevante no texto analisado diz respeito ao uso de determinados tempos verbais que demonstram o posicionamento do locutor/enunciador em relação ao que considera verdadeiro ou falso, produzindo também um efeito de sentido de objetividade ou de subjetividade. Martins (1989) chama as escolhas desses mecanismos de avaliação modalizadora e esclarece que é a forma por meio da qual o locutor demonstra sua posição em relação a um fato. Quando considera algo verdadeiro, o locutor usa o verbo no modo indicativo em orações declarativas, podendo acrescentar expressões que reforçam essa certeza (i.e. certamente, realmente etc.). Quando considera algo falso, contesta-o com maior ou menor veemência. Por fim, se deseja expressar incerteza ou não deseja se comprometer de forma assertiva, o locutor pode empregar o verbo em uma forma modal como o futuro do pretérito ou o subjuntivo acompanhado de uma expressão de dúvida (i.e. talvez, é possível etc.) ou ainda um auxiliar modal (i.e. poder, dever).

No texto de Wilmar Marçal, a modalização não é usada, as orações são declarativas, afirmativas ou negativas, dependendo da posição que assume, com verbos no indicativo. $\mathrm{O}$ quadro 03 traz exemplos de declarações assertivas presentes no texto.

\section{Quadro 03. Orações declarativas assertivas.}

"Quando são organizados, os estudantes conseguem mobilizações
importantes..." "Adentram nos cursos considerados fáceis [...]".
"Fazem festas para comemorar o nada e o inútil [...]".
"Não possuem capacidade e até mesmo vontade para inovar com
qualquer tecnologia ou aprendizado".

Ao estruturar seu discurso dessa forma, com verbos no indicativo e sem a utilização da primeira pessoa ou marcas de modalização, cria-se um efeito de objetividade. "É como se o próprio fato se narrasse a si mesmo. Nesse caso, temos a impressão de que uma verdade objetiva se estabeleceu" (FIORIN, 1990, p. 17). Dessa forma, o locutor constrói seu discurso de forma a convencer seu(s) interlocutor(es) de que o que está sendo dito é verdade e deve ser acatado. Assim, ele atinge seu objetivo maior que é persuadir seu(s) interlocutor(es) a aderir ao seu argumento.

Construindo seus argumentos por meio das escolhas lexicais e da sintaxe, o locutor conduz seu(s) interlocutor(es) ao seu argumento final, os homens e mulheres aos 
quais se refere não são estudantes legítimos, são bandidos e, por isso, não têm lugar na sociedade e devem ser mandados para a cadeia.

A linguagem é uma forma de ação no mundo, dotada de intencionalidade, veiculadora de uma ideologia e caracterizada pela argumentatividade. Não há discurso neutro, "a todo e qualquer discurso subjaz uma ideologia" (KOCH, 1984, p. 19). A respeito das ideologias, Fairclough (2003) salienta que elas são representações, mas podem também ser uma forma de ação que opera sobre as identidades de atores sociais. Ou seja, os discursos são formas de representação e construção da realidade e das identidades, eles são ao mesmo tempo uma forma de agir no mundo e constitutivos dos sujeitos desse mundo.

Assim é o discurso de Marçal. Ele tanto constrói uma realidade quanto atribui uma identidade aos estudantes. Os alunos das ciências humanas, considerada pelo locutor como área de cursos fáceis, são considerados menos legítimos que alunos de outros cursos, e comparados a bandidos e terroristas. Fica clara a posição elitista do locutor que argumenta contra esses alunos que, muitas vezes, dependem de assistência estudantil ou trabalham para custear seus estudos. Esses alunos também são marginalizados por não terem tido a oportunidade de ingressar na universidade aos 17 ou 18 anos e por buscarem uma educação universitária considerada tardia, aos 30 anos. Por fim, o locutor argumenta a favor da punição arbitrária, mandando os estudantes, em suas palavras "terroristas", para a cadeia, a qual, segundo ele, é sua origem embrionária.

O locutor faz parte de uma "elite simbólica" que, como explica Van Dijk (2008), controla o modo de produção e articulação do discurso, como jornalistas e acadêmicos, e usa sua posição para influenciar as construções sociais da realidade e as práticas sociais. Essa influência pode acontecer por meio do discurso persuasivo, argumentando a favor de uma determinada posição como se ela fosse a legítima. Dessa forma, a elite exerce domínio sobre outras classes sociais e mantém sua hegemonia.

Os efeitos da propagação desse discurso recaem sobre os estudantes e, de certa forma, sobre os profissionais da área das ciências humanas, de modo a discriminá-los e subjugá-los. É sabido que em todas as áreas do conhecimento há bons e maus estudantes e profissionais. Todavia, é inconcebível generalizar a qualificação negativa a todos das ciências humanas, contrapondo-os aos estudantes de outras áreas, os quais têm a qualificação positiva. Além disso, esse discurso tenta construir a representação da inutilidade daqueles que atuam nas ciências humanas e, consequentemente, das suas disciplinas, o que é inaceitável.

Foucault (1988) defende que o discurso atua tanto como forma de transmissão e produção de poder, quanto como forma de expô-lo, enfraquecê-lo e de possibilitar impedi-lo. Assim, por meio de contradiscursos, pode-se contestar esse discurso discriminatório e elitista expondo sua intenção de dominação. 


\section{Considerações finais}

Nesse artigo, busquei analisar, com base na Análise de Discurso Crítica, aliada à Semântica Argumentativa, a construção de sentido, o discurso e a construção de identidades em um texto de opinião. A análise feita me possibilitou afirmar que o principal recurso usado pelo locutor foi a seleção lexical, além da avaliação modalizadora, para construir seus argumentos e direcionar a construção de sentido.

Um texto de opinião é altamente argumentativo e os recursos linguísticos utilizados são responsáveis por alcançar o objetivo de persuadir o(s) interlocutor(es) de uma forma aparentemente neutra e objetiva. Acredito que, no texto analisado, a seleção de substantivos e adjetivos e a sintaxe utilizada possibilitaram alcançar esse objetivo. No entanto, uma análise cuidadosa desses recursos revelou a intencionalidade e subjetividade do locutor, além da ideologia subjacente a seu discurso, que é influenciado por suas experiências prévias e seu papel, posição e relações sociais.

Com base nas interpretações que desenvolvi com a análise e nos pressupostos da Análise de Discurso Crítica, defendo que discursos como esse sejam questionados e contestados para que não se privilegie um único posicionamento e incorra-se na falácia de considerá-los naturais. Portanto, espero que essa análise possa contribuir para a contestação de discursos opressores como este, expondo-os e incitando contradiscursos que os confrontem.

\section{Referências bibliográficas}

BEIJAARD, D.; MEIJER, P.; VERLOOP, N. Reconsiderando a pesquisa sobre a identidade profissional de professores. Trad. Bras. Em: REIS, S.; VAN VEEN, K.; GIMENEZ, T. (Orgs.). Identidades de professores de línguas. Londrina: EDUEL, 2011. p. 1-45.

CHOULIARAKI, L.; FAIRCLOUGH, N. Discourse in late modernity: rethinking critical discourse analysis. Edinburgh: Edinburgh University Press, 1999.

DA CAL, E.G. Língua e estilo de Eça de Queiroz. Trad. Bras. Rio de Janeiro: Edições Tempo Brasileiro LTDA, 1969.

DERRIDA, Jacques. Writing and difference. London: Routledge, 1978.

DUCROT, O. Dire et ne pas dire: principe de sémantique linguistique. $3^{\mathrm{e}}$. ed. Paris: Hermann, 1991.

FAIRCLOUGH, N. A dialectical-relational approach to critical discourse analysis in social research. In: WODAK, R.; MEYER, M. (Eds.). Methods of Critical Discourse Analysis. $2^{\text {nd }}$. ed. London: SAGE, 2012. p. 162-186.

Language and globalization. London; New York: Routledge, 2006. 
FAIRCLOUGH, N. Analysing discourse: textual analysis for social research. London; New York: Routledge, 2003. 1995.

Critical Discourse Analysis: the critical study of language. New York: Longman,

FIORIN, J.L. Elementos de Análise do Discurso. 13a . ed. São Paulo: Contexto, 2005.

Linguagem e idologia. $2^{\text {a }}$ ed. São Paulo: Ática, 1990.

FOUCAULT, Michel. História da sexualidade I: a vontade de saber. Trad. Bras. Rio de Janeiro: Edições Graal, 1988.

GIDDENS, A. Modernidade e identidade. Trad. Bras. Rio de Janeiro: Zahar, 2002.

HALL, S. Quem precisa de identidade? Em: SILVA, T.T. da (Org.). Identidade e diferença: a perspectiva dos estudos culturais. 10a . ed. Petrópolis: Vozes, 2011a. p 103133.

A identidade cultural na pós-modernidade. Trad. Bras. $11^{\text {a }}$. ed. Rio de Janeiro: DP \& A, 2011 .

KERBRAT-ORECCHIONI, C. L'enonciation: de la subjectivité dans le langage. $4^{\mathrm{e}}$. ed. Paris: Armand, 1999.

KOCH, I.G.V. Argumentação e linguagem. São Paulo: Cortez, 1984.

MARTINS, N.S. Introdução à estilística: a expressividade na língua portuguesa. São Paulo: T. A. Queiroz; EdUSP, 1989.

MOITA LOPES, Luiz Paulo da. Identidades fragmentadas: a construção discursiva de raça, gênero e sexualidade em sala de aula. Campinas: Mercado de Letras, 2002.

OLIVEIRA, E.G. de. Argumentação: da Idade Média ao Século XX. Signum. Londrina, UEL, n. 7, v. 2, p. 109-131, 2004.

.; AZEVEDO, M.C.H.R. de; NASCIMENTO, S.S. Recursos linguísticoargumentativos no discurso publicitário. Línguas \& Letras. Cascavel, UNIOESTE, v. 9, n. 16, p. 119-135, 2008.

ORLANDI, E.P. Análise do Discurso: princípios e procedimento. 10ª ed. Campinas, SP: Pontes, 2012.

PIRES DE OLIVEIRA, Roberta. Semântica. Em: MUSSALIM, F.; BENTES, A.C. (Orgs.). Introdução à Linguística: domínios e fronteiras. v. 2. São Paulo: Cortez, 2004.

VAN DIJK, Teun. Discurso e poder. São Paulo: Contexto, 2008. 
WODAK, R.; MEYER, M.. Critical Discourse Analysis: history, agenda, theory and methodology. In: WODAK, R.; MEYER, M. (Eds.). Methods of Critical Discourse Analysis. $2^{\text {nd }}$. ed. London: SAGE, 2012. p. 1-33.

WOODWARD, K. Identidade e diferença: uma introdução teórica e conceitual. Em: SILVA, T.T. da (Org.). Identidade e diferença: a perspectiva dos estudos culturais. $10^{\mathrm{a}}$. ed. Petrópolis: Vozes, 2011. p. 7-72.

Artigo recebido em: março de 2016.

Aprovado e revisado em: junho de 2016.

Publicado em: agosto de 2016

\section{Para citar este texto:}

CAMPOS, Alcione Gonçalves. Construção discursiva de identidades sociais: entre o bom e o mau. Entremeios [Revista de Estudos do Discurso], Seção Estudos, Programa de Pósgraduação em Ciências da Linguagem (PPGCL), Universidade do Vale do Sapucaí, Pouso Alegre (MG), vol. 13, p. 45-58, jul. - dez. 2016.

DOI: http://dx.doi.org/10.20337/ISSN2179-3514revistaENTREMEIOSvol13pagina45a58 